\title{
Serum sex hormone-binding globulin and testosterone in relation to cardiovascular disease risk factors in young men: a population-based study
}

\author{
D Canoy, T M Barber ${ }^{1}$, A Pouta ${ }^{2}$, A L Hartikainen ${ }^{3}$, M I McCarthy ${ }^{4,5}$, 5 Franks ${ }^{6}$, \\ M R Järvelin 2,7,8,9,10, J S Tapanainen ${ }^{3,11}$, A Ruokonen ${ }^{12,13}$, I T Huhtaniemi' \\ and $\mathbf{H}$ Martikainen ${ }^{3}$
}

Cancer Epidemiology Unit, Nuffield Department of Population Health, University of Oxford, Richard Doll Building, Roosevelt Drive, Oxford OX3 7LF, UK, 'Department of Metabolic and Vascular Health, Warwick Medical School, University of Warwick, Coventry, UK, ${ }^{2}$ Department of Children and Young People and Families, National Institute for Health and Welfare, Oulu, Finland, ${ }^{3}$ Department of Obstetrics and Gynaecology, Oulu University Hospital and University of Oulu, Oulu, Finland, ${ }^{4}$ Oxford Centre for Diabetes, Endocrinology and Metabolism, University of Oxford, Oxford, UK, ${ }^{5}$ Wellcome Trust Centre for Human Genetics, University of Oxford, Oxford, UK, ${ }^{6}$ Department of Surgery and Cancer, Imperial College London, Institute of Reproductive and Developmental Biology, London, UK, ${ }^{7}$ Department of Epidemiology and Biostatistics, Imperial College London, MRC-Health Protection Agency Centre for Environment and Health, and School of Public Health, London, UK, ${ }^{8}$ Institute of Health Sciences, University of Oulu, Oulu, Finland, ${ }^{9}$ Biocenter Oulu, University of Oulu, Oulu, Finland, ${ }^{10}$ Unit of Primary Care, Oulu University Hospital, Oulu, Finland, ${ }^{11}$ Department of Obstetrics and Gynecology, Helsinki University Central Hospital and University of Helsinki, Helsinki, Finland, ${ }^{12}$ Department of Clinical Chemistry, University of Oulu, Oulu, Finland and ${ }^{13}$ NorLab Oulu, Oulu University Hospital, Oulu, Finland

Correspondence should be addressed to D Canoy

Email

dexter.canoy@ceu.ox.ac.uk

\begin{abstract}
Objective: Reduced sex hormone-binding globulin (SHBG) concentration predicts insulin resistance and type 2 diabetes, but its association with cardiovascular disease (CVD) risk is unclear. We examined the association between SHBG and cardiovascular risk factors, independently of total testosterone (TT), in young men.

Design: Observational, cross-sectional study.

Setting: General community.

Participants: The study included 2716 men aged 31 years in the Northern Finland Birth Cohort in 1996 with clinical examination data and fasting blood samples.

Outcome variables: Blood pressure (BP), lipids and C-reactive protein (CRP) as biological CVD risk markers.

Results: SHBG concentration was significantly and inversely related to systolic and diastolic BP, triglycerides and CRP, but positively to HDL cholesterol after adjusting for insulin, BMI, waist circumference, smoking, education and physical activity (all $P<0.05$ ). These linearly graded associations persisted with additional adjustment for TT. SHBG was significantly associated with total cholesterol only with adjustment for covariates and TT $(P<0.05)$. The direction and magnitude of associations between TT and risk factors were variable, but further adjustment for insulin, adiposity and SHBG showed positive associations between TT and BP, total and LDL-cholesterol and triglycerides and an inverse association with CRP (all $P<0.05$ ), but its relation with HDL-cholesterol was no longer significant.

Conclusions: In this cohort of young adult men, higher SHBG concentration was associated with a more favourable CVD risk profile, independently of TT. SHBG concentration modified the associations of TT with CVD risk factors.
\end{abstract}




\section{Introduction}

First reported in 1967 (1), sex hormone-binding globulin (SHBG) is the specific binding protein for sex steroids in the blood plasma and it regulates the availability of free testosterone (FT) and oestradiol to hormone-responsive tissues and their metabolic clearance rate $(2,3)$. In men, over $40 \%$ of total testosterone (TT) in circulation is bound to SHBG. Although SHBG has traditionally been considered a passive carrier protein, it could have an important biological function of its own. It is known to modify local steroid hormone effects (4) by interacting specifically with high-affinity receptors on cell membranes and participate in steroid hormone signal transduction at the cell membrane independently of the classical intracellular androgen receptors $(2,5,6)$. However, the wider clinical implications of this function remain to be elucidated.

Numerous studies have shown that reduced blood concentrations of SHBG are associated with increased risk of insulin resistance, type 2 diabetes, obesity and the metabolic syndrome $(7,8,9,10,11,12,13,14,15)$ but the role of SHBG in the aetiology of cardiovascular disease (CVD) remains unclear. Studies investigating associations between SHBG and cardiovascular risk have focused only on a few biological risk markers, such as dyslipidaemia, were based on relatively small sample sizes, or did not explore associations independently of adiposity and insulin $(16,17,18,19,20,21)$. As insulin is known to suppress hepatic production of SHBG (22) and its elevated concentration has been closely associated with dyslipidaemia, hypertension and incident coronary heart disease $(23,24)$, it may play a role in explaining the relationship between low SHBG and increased CVD risk. Further, testosterone is closely correlated with, and may influence, SHBG concentration $(25,26)$. As low testosterone is associated, albeit inconsistently, with insulin resistance, type 2 diabetes $(7,8$, $9,27,28)$ and atherosclerosis $(27,29)$, it is therefore unclear if the observed associations between SHBG and CVD risk factors are simply explained by testosterone. We examined the relationship between SHBG and risk factors of CVD, independently of testosterone levels, in a population-based cohort of young adult men.

\section{Subjects and methods}

\section{Study population}

The Northern Finland Birth Cohort (NFBC) consists of 12231 unselected births (representing 96.3\% of all births) of women from the Finnish provinces of Oulu and Lapland in 1966 (30). The number of children born alive was 12058 (52\% boys). In 1997, we sent a health and lifestyle questionnaire to $97 \%$ of the birth cohort (at age 31 years), and invited those living in Northern Finland and in the Helsinki area $(n=8463)$ for a clinical examination, of whom 6033 men and women attended and gave fasting blood samples. The current study sample is limited to men $(n=2716)$ aged 31 years who had given informed consent, had attended clinical examination and had a blood sample taken for measurement of SHBG and testosterone concentrations. The questionnaires provided health and lifestyle data including information on smoking, educational qualification and physical activity. Of those who were invited to attend the clinical examination, we found no statistically significant difference in birth weight $(P=0.99)$ nor in educational attainment $(P=0.06)$ or cigarette smoking habit $(P=0.39)$ at age 31 years when comparing men who attended the clinical examination with those who did not.

The University of Oulu Ethics committee approved the conduct of the study.

\section{Anthropometric and biochemical measurements}

We measured blood pressure (BP) (average of two separate measurements) taken with a mercury sphygmomanometer in a sitting position after 15 min of rest (31). We obtained anthropometric measurements including weight, height and waist circumference, and calculated BMI as weight/ height ${ }^{2}$. Participants gave blood samples between 0800 and $1100 \mathrm{~h}$ following an overnight fast, which were centrifuged immediately and the serum stored at $-20^{\circ} \mathrm{C}$. Assays were carried out within 7 days of the samples being taken. We analysed serum SHBG by immunofluorometric assay (Perkin Elmer-Wallac, Ltd, Turku, Finland) and serum testosterone by an automated chemiluminescence system (ACS-180, Ciba-Corning, Inc., Medfield, MA, USA), and calculated free testosterone (cFT) using Vermeulen's equation (32). We analysed fasting insulin by radioimmunoassay (Pharmacia Diagnostics), fasting glucose by glucose dehydrogenase method (Granutest 250, Diagnostica Merck) and high sensitivity C-reactive protein (CRP) by an immunoenzymometric assay (Medix Biochemica, Espoo, Finland). We determined cholesterol (total, HDL and LDL) and triglycerides using a Hitachi 911 automatic analyser and commercial reagents (Boehringer Mannheim). Intra- and inter-assay coefficients of variation (CV) were 1.3 and 5.1\% for SHBG, respectively, 
and 4 and 5.6\% for TT, respectively. For insulin, glucose, lipids and CRP, intra-assay CV did not exceed 5.3\% and inter-assay $\mathrm{CV}$ did not exceed $7.6 \%$. The sensitivities of TT and insulin assays were $0.35 \mathrm{nmol} / \mathrm{l}$ and $14.4 \mathrm{pmol} / \mathrm{l}$ respectively.

We defined those with metabolic syndrome as having any three of the following characteristics: waist circumference $\geq 94 \mathrm{~cm}$, triglycerides $\geq 1.7 \mathrm{mmol} / \mathrm{l}$, HDL-cholesterol $<1.0 \mathrm{mmol} / \mathrm{l}$, systolic $\mathrm{BP} \geq 130$ or diastolic $\mathrm{BP}$ $\geq 85 \mathrm{mmHg}$ and plasma glucose $\geq 5.5 \mathrm{mmol} / 1$ (33).

\section{Statistical analysis}

We determined the separate relationships between SHBG and an intermediate risk marker of CVD using regression models. We log-transformed triglycerides, insulin and CRP values before linear regression analyses. We conducted similar analyses for TT and cFT, as well as analyses that used metabolic syndrome as the outcome variable. To examine systematically the impact of potential confounders, we analysed data by adjusting sequentially for smoking, education and physical activity and then additionally for fasting insulin and adiposity (BMI and waist circumference) in separate models. We also calculated the homeostatic assessment model for insulin resistance (HOMA-IR) (34) and examined the impact of using this parameter, rather than insulin, in our regression models.

To show the relative independent associations of SHBG and TT on cardiovascular risk outcomes, we adjusted these two exposure variables for each other in the multivariate regression models. We also examined the distribution of cardiovascular risk factors across SHBG and TT quartiles based on multivariate-adjusted models to demonstrate the magnitude of cardiovascular risk across the distribution of SHBG and TT in our study population. Estimates were presented with their standard error or 95\% CI, and a $P$ value $<0.05$ was considered statistically significant. All analyses were conducted using the statistics package Stata 11 MP (College Station, TX, USA).

\section{Results}

In this cohort, mean (s.D.) SHBG, TT and calculated cFT were 33.3 (s.D.=13.3) nmol/1, 21.6 (s.D.=6.5) nmol/l and 481 (s.D. = 144) pmol/1 respectively. Mean BMI was 25.2 (s.D. $=3.6) \mathrm{kg} / \mathrm{m}^{2}$ and $8.4 \%$ of men were obese (BMI $\geq 30 \mathrm{~kg} / \mathrm{m}^{2}$ ). Table 1 provides the distribution of characteristics across quartiles of SHBG. Higher SHBG quartile

Table 1 Characteristics of men aged 31 years in the NFBC 1966 study by SHBG concentration. Data presented as mean (s.D.) for continuous variables, except for triglycerides, insulin and C-reactive protein which are presented as median (25th to 75th percentile range), and percentage for categorical variables.

\begin{tabular}{|c|c|c|c|c|c|}
\hline \multirow[b]{2}{*}{ Variables } & \multicolumn{4}{|c|}{ SHBG $(\mathrm{nmol} / \mathrm{l})$} & \multirow[b]{2}{*}{ All } \\
\hline & $<24.1$ & $24.1-31.5$ & $31.6-40.4$ & $>40.4$ & \\
\hline$n$ & 682 & 679 & 677 & 678 & 2716 \\
\hline SHBG (nmol/l) & $18.6(3.9)$ & $27.8(2.2)$ & $35.7(2.6)$ & $51.4(10.2)$ & $33.3(13.3)$ \\
\hline Total testosterone $(\mathrm{nmol} / \mathrm{l})$ & $16.8(5.4)$ & $20.2(4.6)$ & $22.6(5.0)$ & $26.8(6.3)$ & $21.6(6.5)$ \\
\hline Free testosterone $(\mathrm{pmol} / \mathrm{l})$ & $478(182)$ & $490(130)$ & $486(128)$ & $469(130)$ & $481(144)$ \\
\hline BMI $\left(\mathrm{kg} / \mathrm{m}^{2}\right)$ & $27.7(4.0)$ & $25.5(3.0)$ & $24.2(2.9)$ & $23.5(2.9)$ & $25.2(3.6)$ \\
\hline Waist circumference $(\mathrm{cm})$ & $95.9(10.4)$ & $89.8(8.3)$ & $86.2(8.1)$ & 83.9 (7.9) & $88.9(9.8)$ \\
\hline Systolic blood pressure $(\mathrm{mmHg})$ & $134.6(13.2)$ & $131.5(12.9)$ & $129.0(12.5)$ & $128.5(12.9)$ & $130.9(13.1)$ \\
\hline Diastolic blood pressure $(\mathrm{mmHg})$ & $85.3(12.3)$ & $80.9(10.8)$ & $79.4(11.4)$ & $78.1(11.5)$ & $80.9(11.8)$ \\
\hline Total cholesterol (mmol/l) & $5.41(1.04)$ & $5.19(1.02)$ & $5.12(1.00)$ & $5.15(0.97)$ & $5.22(1.01)$ \\
\hline LDL-cholesterol (mmol/l) & $3.37(0.89)$ & $3.23(0.89)$ & $3.17(0.89)$ & $3.17(0.91)$ & $3.23(0.90)$ \\
\hline HDL-cholesterol (mmol/l) & $1.28(0.30)$ & $1.39(0.28)$ & $1.45(0.33)$ & $1.53(0.35)$ & $1.41(0.33)$ \\
\hline Triglycerides (mmol/l) & $1.52(1.18)$ & $1.14(0.69)$ & $0.98(0.60)$ & $0.91(0.53)$ & $1.11(1.77)$ \\
\hline Plasma glucose $(\mathrm{mmol} / \mathrm{l})$ & $5.24(0.59)$ & $5.17(0.44)$ & $5.16(0.70)$ & $5.12(0.63)$ & $5.17(0.60)$ \\
\hline Serum insulin $(\mathrm{pmol} / \mathrm{l})$ & $70.3(34.4)$ & $56.9(23.0)$ & $51.7(20.8)$ & $48.8(17.9)$ & $56.0(25.1)$ \\
\hline HOMA-IR index & $2.69(1.65)$ & $1.99(0.91)$ & $1.77(0.69)$ & $1.70(1.02)$ & $2.04(1.19)$ \\
\hline C-reactive protein (mg/l) & $1.00(1.70)$ & $0.70(1.10)$ & $0.60(0.90)$ & $0.50(0.80)$ & $0.70(1.2)$ \\
\hline$\%$ Current smokers $(n)$ & $30.0(202)$ & $27.0(181)$ & $33.9(226)$ & $40.4(272)$ & $32.8(881)$ \\
\hline$\%$ Low educational attainment ${ }^{a}(n)$ & $17.6(120)$ & $16.6(113)$ & $17.6(119)$ & $18.4(125)$ & $17.6(477)$ \\
\hline$\%$ Low physical activity level ${ }^{\mathrm{b}}(n)$ & $63.3(432)$ & $55.1(374)$ & $56.1(380)$ & $54.0(366)$ & $57.1(1552)$ \\
\hline$\%$ Metabolic syndrome ${ }^{c}(n)$ & $36.4(248)$ & $12.5(85)$ & $8.4(57)$ & $5.3(36)$ & $15.7(426)$ \\
\hline
\end{tabular}


was associated higher HDL-cholesterol but with lower $\mathrm{BP}$, total cholesterol, LDL-cholesterol, triglycerides, fasting levels of plasma glucose and insulin, HOMA-IR index and CRP. There was no clear variation in smoking, educational attainment and level of physical activity, but those at the top quartile of SHBG had the highest proportions of current smokers whereas those at the bottom quartile had the highest proportion with low physical activity level. The correlations of SHBG with TT and cFT were 0.59 $(P<0.001)$ and $-0.06(P=0.004)$, respectively, and the BMI-adjusted partial correlations were $0.53(P<0.001)$ and $-0.09(P<0.001)$ respectively.

\section{SHBG, testosterone and the metabolic syndrome}

We first examined the relation of SHBG and TT with metabolic syndrome as the outcome variable (Table 2). The odds ratio for metabolic syndrome decreased with increasing SHBG, independently of other factors including TT, with over $46 \%$ reduced risk associated with $10.6 \mathrm{nmol} / 1$ increase in SHBG concentration. While the risk for metabolic syndrome decreased with increasing TT, this relation did not persist when taking BMI into account. However, with additional adjustment for SHBG, the risk for metabolic syndrome increased with higher TT, with over $38 \%$ excess risk associated with $5.2 \mathrm{nmol} / \mathrm{l}$ increase in TT concentration. Thus, when mutually adjusting for each other (and taking into account other potential confounding factors), SHBG and TT showed independent and opposing associations with metabolic syndrome. Adjusting for smoking, education, physical activity and BMI, the odds ratios (95\% CI) from the second to the fourth quartile of cFT, as compared with the lowest quartile, were 1.31 (0.89-1.92), 1.51 (1.04-2.20) and 2.47 (1.71-3.55), respectively, with $34 \%$ excess risk associated with $110 \mathrm{pmol} / \mathrm{l}$ increase in cFT concentration.

\section{SHBG and cardiovascular risk factors}

Table 3 gives the association between SHBG and cardiovascular risk factors. Adjusting for smoking, education, physical activity and fasting insulin, increasing SHBG concentration was significantly associated with decreasing $\mathrm{BP}$, triglycerides and CRP as well as with increasing HDL-cholesterol (all $P$ for trend $<0.001$ ). These associations were attenuated with additional adjustment for BMI and waist circumference, but the relation remained significant except for total and LDL-cholesterol and systolic BP. With further adjustment for TT, the association persisted, with increasing SHBG associated with decreasing BP, total cholesterol, triglycerides and CRP, and increasing HDL-cholesterol (all $P$ for trend $<0.05$ ). SHBG was unrelated to LDL-cholesterol in models that adjusted for insulin, adiposity or TT. Findings were similar when we used HOMA-IR, instead of insulin, as a covariate in the regression model for each risk factor being studied.

Figures 1 and 2 show the relative difference in BP and lipids across the whole SHBG gradient, taking into account TT and other covariates (full values are shown in the online Supplementary Table S1, see section on

Table 2 Odds ratio $(95 \% \mathrm{Cl}$ ) for metabolic syndrome according to the quartiles of sex hormone-binding globulin (SHBG) or total testosterone in 2716 men aged 31 years in the NFBC 1966 study.

\begin{tabular}{|c|c|c|c|c|}
\hline & $\begin{array}{c}\text { Percentage with } \\
\text { metabolic syndrome }^{a}(n)\end{array}$ & $\begin{array}{l}\text { Adjusted for smoking, } \\
\text { education and physical } \\
\text { activity }\end{array}$ & $\begin{array}{c}\text { Additionally adjusted } \\
\text { for BMI }\end{array}$ & $\begin{array}{c}\text { Additionally adjusted } \\
\text { for SHBG or total } \\
\text { testosterone }^{b}\end{array}$ \\
\hline \multicolumn{5}{|l|}{ SHBG (nmol/l) } \\
\hline$<24.1(n=682)$ & $36.4(248)$ & 1.00 & 1.00 & 1.00 \\
\hline $24.1-31.5(n=679)$ & $12.5(85)$ & $0.25(0.19-0.33)$ & $0.41(0.30-0.56)$ & $0.33(0.24-0.47)$ \\
\hline $31.6-40.4(n=677)$ & $8.4(57)$ & $0.15(0.11-0.21)$ & $0.39(0.28-0.57)$ & $0.28(0.19-0.42)$ \\
\hline All (per $10.6 \mathrm{nmol} / \mathrm{l})$ & $15.7(426)$ & $0.42(0.37-0.47)$ & $0.65(0.57-0.74)$ & $0.54(0.46-0.63)$ \\
\hline \multicolumn{5}{|c|}{ Total testosterone (nmol/l) } \\
\hline$<17.4(n=687)$ & $23.3(160)$ & 1.00 & 1.00 & 1.00 \\
\hline $17.4-21.9(n=678)$ & $18.0(122)$ & $0.70(0.53-0.92)$ & $1.46(1.05-2.03)$ & $2.01(1.42-2.83)$ \\
\hline $21.1-25.6(n=674)$ & $11.3(76)$ & $0.40(0.30-0.55)$ & $0.93(0.65-1.34)$ & $1.67(1.12-2.48)$ \\
\hline$>25.6(n=677)$ & $10.0(68)$ & $0.34(0.25-0.46)$ & $1.13(0.77-1.66)$ & $3.17(2.06-5.03)$ \\
\hline All (per $5.2 \mathrm{nmol} / \mathrm{l})$ & $15.7(426)$ & $0.68(0.62-0.77)$ & $1.00(0.88-1.12) *$ & $1.38(1.20-1.60)$ \\
\hline
\end{tabular}

All $P$ for trend $<0.001$ except $* P>0.05$.

aWith any three of the following features: waist circumference $\geq 94 \mathrm{~cm}$, triglycerides $\geq 1.7 \mathrm{mmol} / \mathrm{l}$, $\mathrm{HDL}$-cholesterol $<1.0 \mathrm{mmol} / \mathrm{l}$, systolic blood pressure $\geq 130 \mathrm{mmHg}$ or diastolic blood pressure $\geq 85 \mathrm{mmHg}$, and plasma glucose $\geq 5.56 \mathrm{mmol} / \mathrm{l}$.

SHBG and total testosterone mutually adjusted for each other in the model. 
Table 3 Relative difference $(\beta$ coefficient $(95 \% \mathrm{Cl})$ ) in cardiovascular risk markers per $10.6 \mathrm{nmol} / \mathrm{l}$ higher sex hormone-binding globulin in 2716 men aged 31 years in the NFBC 1966 study.

\begin{tabular}{l}
\hline $\begin{array}{l}\text { Cardiovascular risk } \\
\text { markers }\end{array}$ \\
\hline Systolic blood \\
pressure $(\mathrm{mmHg})$ \\
Diastolic blood \\
pressure $(\mathrm{mmHg})$ \\
Total cholesterol \\
(mmol/l) \\
LDL-cholesterol \\
(mmol/l) \\
HDL-cholesterol \\
(mmol/l) \\
Log-triglycerides \\
(mmol/l) \\
Log-C-reactive \\
protein (mg/l)
\end{tabular}

\begin{tabular}{ccc}
$\begin{array}{c}\text { Adjusted for smoking, } \\
\text { education and physical } \\
\text { activity }\end{array}$ & $\begin{array}{c}\text { Additionally adjusted for } \\
\text { fasting insulin }\end{array}$ \\
\hline$-2.1(-2.6 \text { to }-1.7)^{*}$ & & $-1.4(-1.9$ to -1.0$) *$ \\
$-2.3(-2.7 \text { to }-1.9)^{*}$ & $-1.5(-2.0$ to -1.1$) *$ \\
$-0.09(-0.12 \text { to }-0.05)^{*}$ & $-0.03(-0.07$ to 0.00$)$ \\
$-0.06(-0.10 \text { to }-0.03)^{*}$ & $-0.03(-0.06$ to 0.00$)$ \\
$0.08(0.07$ to 0.09$) *$ & $0.07(0.06$ to 0.08$) *$ \\
$-0.17(-0.18 \text { to }-0.15)^{*}$ & $-0.12(-0.14$ to -0.11$) *$ \\
$-0.32(-0.38$ to -0.27$) *$ & $-0.25(-0.30$ to -0.19$) *$ \\
\hline
\end{tabular}

\begin{tabular}{c}
\hline $\begin{array}{c}\text { Additionally adjusted } \\
\text { for BMI and waist } \\
\text { circumference }\end{array}$ \\
\hline$-0.5(-0.9$ to 0.0$)$ \\
$-0.6(-1.1 \text { to }-0.2)^{\dagger}$ \\
$0.02(-0.02$ to 0.05$)$ \\
$0.02(-0.01$ to 0.06$)$ \\
$0.05(0.04$ to 0.06$)$ *
\end{tabular}

\begin{tabular}{c}
$\begin{array}{c}\text { Additionally adjusted } \\
\text { for total testosterone }\end{array}$ \\
\hline$-1.0(-1.5 \text { to }-0.4)^{\dagger}$ \\
$-1.1(-1.6 \text { to }-0.6)^{*}$ \\
$-0.05(-0.09 \text { to }-0.01)^{\dagger}$ \\
$0.00(-0.04$ to 0.04$)$ \\
$0.04(0.03 \text { to } 0.05)^{*}$
\end{tabular}

$-0.09(-0.11$ to -0.07$) *-0.15(-0.17$ to -0.13$)$ *

$-0.13(-0.20 \text { to }-0.07)^{*}-0.08(-0.16 \text { to }-0.01)^{\dagger}$

NFBC, Northern Finland Birth Cohort; Log, natural logarithmic transformation; all $P>0.05$ except: ${ }^{\star} P<0.001,{ }^{\dagger} P<0.05$.

supplementary data given at the end of this article). The relation of SHBG with these cardiovascular risk factors, independently of TT, tended to be graded and linear (except for LDL-cholesterol). The online Supplementary Table S1 also shows the magnitude of the difference in risk. For example, those in the top fourths of SHBG distribution had lower systolic BP by 2.8 (95\% CI 1.0-4.5) $\mathrm{mmHg}$, diastolic BP by 3.7 (2.1 to 5.2 ) $\mathrm{mmHg}$, and total cholesterol by 0.16 (95\% CI 0.03-0.30) $\mathrm{mmol} / \mathrm{l}$ as compared with those in the bottom fourths.

\section{Testosterone and cardiovascular risk factors}

After adjusting for smoking, education, physical activity and fasting insulin, increasing TT was significantly associated with decreasing $\mathrm{BP}$, triglycerides and CRP, and increasing HDL-cholesterol as given in Table 4 (all $P$ for trend $<0.05)$. Adjusting for insulin and adiposity attenuated the associations, but further adjustment for SHBG changed the direction of the slope of the association between TT and the outcome measures (except for CRP). With adjustment for SHBG, increasing TT was associated with increasing BP, total and LDL-cholesterol, and triglycerides as well as with decreasing CRP (all $P$ for trend $<0.05$ ); however, the relation with HDL-cholesterol was no longer significant. Findings were similar after substituting insulin with HOMA-IR in the regression model for all cardiovascular risk factors considered in this study.

When fasting insulin was used as an outcome variable, higher TT was associated with lower fasting insulin levels even after adjusting for adiposity and other covariates
$(P=0.007)$, but this association did not persist when SHBG was taken into account $(P>0.05)$.

Figures 1 and 2 show the relative difference in BP and lipids across the whole gradient of TT after adjusting for SHBG and other covariates (full values are shown in the

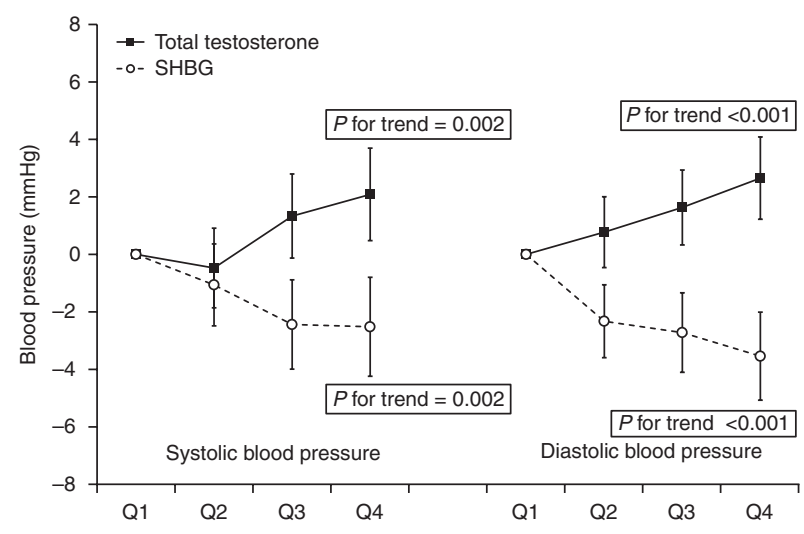

\section{Figure 1}

Relative difference ( $\beta$ coefficient $(95 \% \mathrm{Cl})$ ) in systolic and diastolic blood pressure according to the quartiles of sex hormone-binding globulin (SHBG) or total testosterone in 2716 men in the Northern Finland Birth Cohort 1966 study. Values are adjusted for smoking, education, physical activity, fasting insulin, BMI, waist circumference and either total testosterone or SHBG. $P$ values indicate trends across quartile categories. Coefficients indicate that blood pressure for that group could be higher (positive values) or lower (negative values) as compared with the mean blood pressure of the reference group (quartile 1 ). 


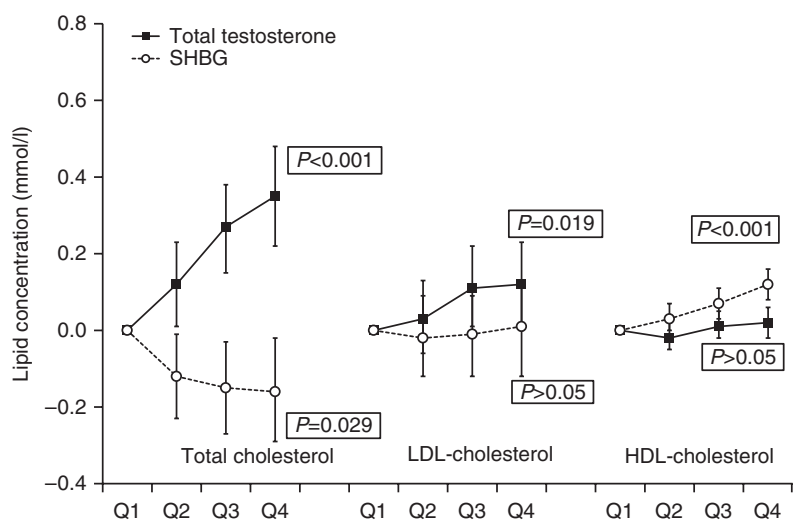

Figure 2

Relative difference ( $\beta$ coefficient $(95 \% \mathrm{CI})$ ) in total, $\mathrm{LDL}$, and $\mathrm{HDL}$-cholesterol according to the quartiles of sex hormonebinding globulin (SHBG) or total testosterone in 2716 men in the Northern Finland Birth Cohort 1966 study. Values are adjusted for smoking, education, physical activity, fasting insulin, BMI, waist circumference, and either total testosterone or SHBG. $P$ values indicate trends across quartile categories. Coefficients indicate that cholesterol for that group could be higher (positive values) or lower (negative values) as compared with the mean cholesterol of the reference group (quartile 1).

online Supplementary Table S2, see section on supplementary data given at the end of this article). The relation of TT with these cardiovascular risk factors tended to be graded and linear (except for HDL-cholesterol). The online Supplementary Table S2 also gives the magnitude of the difference in risk. For example, those in the top fourths of TT distribution had higher systolic BP by 0.7 (95\% CI $0.2-1.2) \mathrm{mmHg}$, diastolic BP by 0.8 (95\% CI $0.3-1.2)$ $\mathrm{mmHg}$ and total cholesterol by 0.12 (95\% CI 0.08-0.16) $\mathrm{mmol} / \mathrm{l}$ as compared with those in the bottom fourths.

After adjusting for smoking, education, physical activity, fasting insulin, BMI and waist circumference, increasing cFT was significantly and positively related to $\mathrm{BP}$, total cholesterol and triglycerides (online Supplementary Table S3). The direction and magnitude of the associations with the various risk factors were similar to those of covariate- and SHBG-adjusted associations for TT, except for CRP wherein the magnitude of the reduction in CRP was twice as big as the association seen for cFT. For example, a one quartile increase in TT $(5.2 \mathrm{nmol} / \mathrm{l})$ and cFT $(110 \mathrm{pmol} / \mathrm{l})$ was associated with an increase in systolic BP by 0.7 (95\% CI $0.2-1.2)$ and $0.6(0.2-1.1)$ respectively; and an increase in cholesterol by 0.12 (95\% CI $0.08-0.16)$ and $0.10(0.07-0.14)$ respectively.

\section{Discussion}

In this cohort of young adult men, increasing serum SHBG concentration was generally associated with a better cardiovascular risk profile. Higher SHBG concentration was associated with lower BP, cholesterol, triglycerides and CRP as well as higher HDL-cholesterol, independently of TT, insulin, adiposity and other potential confounding factors. The magnitude of the association varied across CVD risk factors, but the associations were largely linear

Table 4 Relative difference $(\beta$ coefficient $(95 \% \mathrm{Cl}))$ in cardiovascular risk markers per $5.2 \mathrm{nmol} / \mathrm{l}$ higher total testosterone in 2716 men aged 31 years in the NFBC 1966 study.

\begin{tabular}{|c|}
\hline $\begin{array}{l}\text { Cardiovascular risk } \\
\text { markers }\end{array}$ \\
\hline $\begin{array}{l}\text { Systolic blood } \\
\text { pressure }(\mathrm{mmHg})\end{array}$ \\
\hline $\begin{array}{l}\text { Diastolic blood } \\
\text { pressure }(\mathrm{mmHg})\end{array}$ \\
\hline $\begin{array}{l}\text { Total cholesterol } \\
(\mathrm{mmol} / \mathrm{l})\end{array}$ \\
\hline $\begin{array}{l}\text { LDL-cholesterol } \\
(\mathrm{mmol} / \mathrm{l})\end{array}$ \\
\hline $\begin{array}{l}\text { HDL-cholesterol } \\
(\mathrm{mmol} / \mathrm{l})\end{array}$ \\
\hline $\begin{array}{l}\text { Log-triglycerides } \\
\text { (mmol/l) }\end{array}$ \\
\hline $\begin{array}{l}\text { Log-C-reactive } \\
\text { protein }(\mathrm{mg} / \mathrm{l})\end{array}$ \\
\hline
\end{tabular}

\begin{tabular}{ccc}
$\begin{array}{c}\text { Adjusted for smoking, } \\
\text { education and physical } \\
\text { activity }\end{array}$ & & $\begin{array}{c}\text { Additionally adjusted } \\
\text { for fasting insulin }\end{array}$ \\
\hline$-0.8(-1.3 \text { to }-0.4)^{*}$ & & $-0.3(-0.8$ to 0.1$)$ \\
$-0.8(-1.2 \text { to }-0.4)^{*}$ & & $-0.3(-0.7$ to 0.1$)$ \\
$0.03(-0.01$ to 0.06$)$ & & $0.06(0.03 \text { to } 0.10)^{*}$ \\
$-0.01(-0.04$ to 0.02$)$ & & $0.01(-0.02$ to 0.04$)$ \\
$0.06(0.05 \text { to } 0.07)^{*}$ & & $0.05(0.04 \text { to } 0.06)^{*}$ \\
$-0.03(-0.05 \text { to }-0.01)^{\dagger}$ & $0.01(-0.01$ to 0.02$)$ \\
$-0.28(-0.33$ to -0.22$) *$ & $-0.22(-0.28 \text { to }-0.16)^{*}$ \\
\hline
\end{tabular}

\begin{tabular}{ccc}
$\begin{array}{c}\text { Additionally adjusted } \\
\text { for BMI and waist } \\
\text { circumference }\end{array}$ & & $\begin{array}{c}\text { Additionally adjusted } \\
\text { for SHBG }\end{array}$ \\
\hline $0.4(-0.1$ to 0.9$)$ & & $0.7(0.2 \text { to } 1.2)^{\dagger}$ \\
$0.4(-0.0$ to 0.8$)$ & & $0.8(0.3 \text { to } 1.2)^{\dagger}$ \\
$0.10(0.07 \text { to } 0.14)^{*}$ & & $0.12(0.08 \text { to } 0.16)^{*}$ \\
$0.05(0.02 \text { to } 0.08)^{\dagger}$ & & $0.04(0.01 \text { to } 0.08)^{\dagger}$ \\
$0.03(0.02 \text { to } 0.04)^{*}$ & & $0.01(-0.00$ to 0.02$)$ \\
$0.04(0.03 \text { to } 0.06)^{*}$ & $0.11(0.09 \text { to } 0.12)^{*}$ \\
\hline $0.13(-0.19$ to -0.07$) *$ & $-0.10(-0.17 \text { to }-0.03)^{\dagger}$ \\
\hline
\end{tabular}

NFBC, Northern Finland Birth Cohort; SHBG, sex hormone-binding globulin; Log, natural logarithmic transformation; All $P>0.05$ except: $* P<0.001$ ${ }^{\dagger} P<0.05$. 
across a wide range of SHBG concentration in this population. Our findings suggest that SHBG may primarily play a role in the cardiovascular health of young men through a number of mediating biological risk factors.

Many studies have previously investigated the separate relation of SHBG with different CVD risk factors (online Supplementary Tables S4 and S5, see section on supplementary data given at the end of this article), but findings in men, particularly of sufficient sample size, remain relatively limited (few studies had $n>1000$ ). Considering that CVD can involve a number of biological pathways, few studies considered examining a number of risk factors from within a single cohort $(15,19,35,36,37)$. Many of the earlier studies have also not accounted for the potential confounding effects of adiposity and insulin. Considering that SHBG and TT concentrations co-vary with one other, it is unclear if findings for SHBG are simply explained by TT. Our study is based on a relatively large sample of young men with a very narrow age range (same year of birth). We examined associations across a number of classical and non-classical risk factors of CVD, and systematically took into account important covariates, such as adiposity and insulin, as well as TT. Our results persisted even when we substituted insulin with HOMA-IR as a covariate in our analyses.

Over $40 \%$ of TT in the circulation is bound with strong affinity to SHBG concentration in men and most of the remaining testosterone is loosely bound to albumin, with only $1-2 \%$ of that circulating as biologically active FT (38). However, direct measures of FT from blood samples for large cohorts are not feasible to do, so it is only estimated from simple, quantitative methods based on the law of mass action (32). Thus, cFT has been suggested to provide an estimate of the biologically active form of testosterone with reasonable accuracy (38). Because SHBG has been traditionally seen to only have a passive role as a carrier protein, and that TT correlates with and explains over $80 \%$ of the variance of FT (39), TT is widely used in many studies that examine the importance of testosterone on health in population-based studies.

However, SHBG could have a biological function on its own other than simply to regulate the levels of the biologically active fraction of testosterone (4). As our findings suggest, it may be involved in the determination of cardiovascular risk, although the underlying mechanism is unclear. As the relation of SHBG with CVD risk factors was independent of testosterone, other pathways could be involved. A study that identified genetic variants associated with SHBG concentration indicates that these genes are likely to be involved in various metabolic pathways, such as lipid and carbohydrate metabolism, liver function and type 2 diabetes (40). It is possible that the association between SHBG and CVD risk factors may have nothing to do with the role of SHBG as testosterone carrier; it responds to a number of metabolic alterations and its concentration may reflect these metabolic perturbations.

Our study has also shown interesting findings for testosterone. Although it has been suggested to play direct and indirect roles in lipid metabolism, regulation of BP and immunomodulation $(41,42,43,44,45,46,47)$, reports on the relationship between testosterone and CVD or its risk factors have been inconsistent $(41,48,49,50)$, and possibly confounded (51). The conflicting findings, particularly between endogenous testosterone and CVD risk factors, could stem from the fact that many studies used the biologically inactive rather than the bioavailable fraction of testosterone (without accounting for the potential influence of SHBG and other potential confounders). In our study, we demonstrated the change in the magnitude and direction of the association of TT with cardiovascular risk factors (except for HDL-cholesterol and CRP) by systematically taking into account various lifestyle factors, insulin, adiposity and SHBG. Because SHBG regulates the availability of the active fraction of testosterone, the SHBGadjusted associations for TT could be indicative of the effects of biologically active FT (as shown by the results for cFT). Nevertheless, age might modify the association between testosterone and CVD risk, which seems to suggest that higher testosterone could be associated with increased CVD risk in younger men, as we have observed in our cohort, but potentially the reverse is true in older men (48). It has been shown that ageing and subclinical chronic diseases that are prevalent in older men are associated with reduced testosterone levels (52). Thus, low testosterone may indicate poor underlying health status and may be predictive of adverse health risks in older men $(48,49)$, but the reverse may be the case in young men.

Interestingly, TT was independently but inversely related with CRP, an association which differed from that of other biological risk markers. This relationship might reflect the effect of androgens in inhibiting the synthesis of pro-inflammatory cytokines, including tumour necrosis factor- $\alpha$ and interleukin-6 (44, 53), which may consequently attenuate the production of downstream markers of inflammation such as CRP.

The recent identification of genetic markers associated with circulating levels of TT found in the SHBG locus (54) could shed light on the nature of the association between TT and CVD risk factors. In a recent study, the association 
between lower TT and CVD risk factors has been investigated using two different analytical approaches (51). On the basis of multivariate regression models (but without adjusting for SHBG, adiposity and insulin as we did in our study), low TT was associated with a more adverse CVD risk profile. In contrast, when using genetic variants of TT as instruments in an instrumental variable analysis (Mendelian randomisation), most of the associations weakened in magnitude and were no longer significant, with the slope of the associations possibly changing in their direction. For example, the regression analysis results showed a significant inverse relationship between TT and systolic BP; in contrast, the instrumental variable analyses suggested a significant positive relationship between TT and systolic BP. Such observations were similar to our findings when we adjusted for various covariates including SHBG (although in their analyses they did not adjust for insulin and adiposity).

The cross-sectional design of this study does not allow us to demonstrate the temporal nature of the associations, and a longitudinal study is warranted. Our findings need to be evaluated across a wider age range, as ageing is related to an increase in SHBG concentration, a fall in androgen levels $(55,56,57)$ and a rise in CVD absolute rates $(58)$. It has been suggested that specific genotypes might influence the binding affinity of SHBG with testosterone and thereby affect the calculation of FT based on the law of mass action, as used in the Vermeulen equation (54) (which is essentially the same as statistically adjusting for SHBG in a regression model). However, the frequency of the allele that has been shown to influence the SHBG binding with testosterone is rare (around 2\%). Within a population perspective, our findings for endogenous TT, when adjusted for SHBG, could still reflect the effects of the biologically active fraction of testosterone. Nevertheless, we could not rule out another factor that might underlie the modulation of both SHBG and TT levels and impact on cardiovascular risk at the same time. Future work may require using the principles of Mendelian inheritance by using genetic variants of SHBG as randomisation instruments $(10,59)$ to enable an unbiased examination of the nature of the relation of SHBG with CVD risk factors and with the development of CVD endpoints.

In this cohort of young men, increasing SHBG concentration was associated with improving the CVD risk profile independently of TT and other factors, suggesting that SHBG may play a role in the cardiovascular health of young men through a number of mediating biological risk factors. Further, SHBG modified the relationship between TT and CVD risk factors.
Understanding the role of SHBG in these different pathways might provide clues to the biological basis for explaining the relationship of SHBG and CVD risk factors.

Supplementary data

This is linked to the online version of the paper at http://dx.doi.org/10.1530/ EJE-13-1046.

\section{Declaration of interest}

The authors declare that there is no conflict of interest that could be perceived as prejudicing the impartiality of the research reported.

\section{Funding}

The Northern Finland Birth Cohort 1966 study has been supported by programme grants from the Academy of Finland and the University of Oulu. Additional grants were received from the European Commission (Quality of Life and Management of Living Resources Program, contract QLG1-CT-2000-01643) for data collection. The study also received support from the Oulu University Hospital for the collection and assay of biological samples. Funding agencies were neither involved in the analysis nor in drafting the manuscript.

\section{Author contribution statement}

M R Järvelin, A L Hartikainen, A Pouta, H Martikainen and A Ruokonen were involved in the conception, design and data acquisition for the Northern Finland Birth Cohort 1966 study. D Canoy analysed the data, and drafted the initial version of the manuscript. $H$ Martikainen, I T Huhtaniemi, T M Barber, J S Tapanainen, S Franks, M I McCarthy, M R Järvelin, A Pouta and A L Hartikainen gave critical intellectual input and contributed in revising subsequent versions of the manuscript. All authors gave their final approval of the version to be published.

\section{References}

1 Pearlman WH \& Crepy O. Steroid-protein interaction with particular reference to testosterone binding by human serum. Journal of Biological Chemistry 1967242 182-189.

2 Kahn SM, Hryb DJ, Nakhla AM, Romas NA \& Rosner W. Sex hormonebinding globulin is synthesized in target cells. Journal of Endocrinology 2002175 113-120. (doi:10.1677/joe.0.1750113)

3 Rosner W. Plasma steroid-binding proteins. Endocrinology and Metabolism Clinics of North America 199120 697-720.

4 Rajala UM, Keinanen-Kiukaanniemi SM, Hirsso PK, Jokelainen JJ, Laakso MA, Hiltunen LA, Ruokonen AO, Harkonen PK \& Timonen MJ. Associations of total testosterone and sex hormone-binding globulin levels with insulin sensitivity in middle-aged Finnish men. Diabetes Care 200730 e13. (doi:10.2337/dc06-1979)

5 Rosner W, Hryb DJ, Khan MS, Nakhla AM \& Romas NA. Sex hormonebinding globulin mediates steroid hormone signal transduction at the plasma membrane. Journal of Steroid Biochemistry and Molecular Biology 199969 481-485. (doi:10.1016/S0960-0760(99)00070-9)

6 Rosner W, Hryb DJ, Khan MS, Nakhla AM \& Romas NA. Androgen and estrogen signaling at the cell membrane via G-proteins and cyclic adenosine monophosphate. Steroids 199964 100-106. (doi:10.1016/ S0039-128X(98)00108-1) 
7 Kupelian V, Page ST, Araujo AB, Travison TG, Bremner WJ \& McKinlay JB. Low sex hormone-binding globulin, total testosterone, and symptomatic androgen deficiency are associated with development of the metabolic syndrome in nonobese men. Journal of Clinical Endocrinology and Metabolism 200691 843-850. (doi:10.1210/ jc.2005-1326)

8 Laaksonen DE, Niskanen L, Punnonen K, Nyyssonen K, Tuomainen TP, Valkonen VP, Salonen R \& Salonen JT. Testosterone and sex hormonebinding globulin predict the metabolic syndrome and diabetes in middle-aged men. Diabetes Care 200427 1036-1041. (doi:10.2337/ diacare.27.5.1036)

9 Ding EL, Song Y, Malik VS \& Liu S. Sex differences of endogenous sex hormones and risk of type 2 diabetes: a systematic review and meta-analysis. Journal of the American Medical Association 2006295 1288-1299. (doi:10.1001/jama.295.11.1288)

10 Ding EL, Song Y, Manson JE, Hunter DJ, Lee CC, Rifai N, Buring JE, Gaziano JM \& Liu S. Sex hormone-binding globulin and risk of type 2 diabetes in women and men. New England Journal of Medicine 2009361 1152-1163. (doi:10.1056/NEJMoa0804381)

11 Vikan T, Schirmer H, Njolstad I \& Svartberg J. Low testosterone and sex hormone-binding globulin levels and high estradiol levels are independent predictors of type 2 diabetes in men. European Journal of Endocrinology 2010162 747-754. (doi:10.1530/EJE-09-0943)

12 Haring R, Volzke H, Spielhagen C, Nauck M \& Wallaschofski H. The role of sex hormone-binding globulin and testosterone in the risk of incident metabolic syndrome. European Journal of Preventive Cardiology 201220 1061-1068. (doi:10.1177/2047487312452965)

13 Bhasin S, Jasjua GK, Pencina M, D'Agostino R Sr, Coviello AD, Vasan RS $\&$ Travison TG. Sex hormone-binding globulin, but not testosterone, is associated prospectively and independently with incident metabolic syndrome in men: the framingham heart study. Diabetes Care 201134 2464-2470. (doi:10.2337/dc11-0888)

14 Li C, Ford ES, Li B, Giles WH \& Liu S. Association of testosterone and sex hormone-binding globulin with metabolic syndrome and insulin resistance in men. Diabetes Care 201033 1618-1624. (doi:10.2337/ dc09-1788)

15 Hong D, Kim YS, Son ES, Kim KN, Kim BT, Lee DJ \& Kim KM. Total testosterone and sex hormone-binding globulin are associated with metabolic syndrome independent of age and body mass index in Korean men. Maturitas $2013 \mathbf{7 4}$ 148-153. (doi:10.1016/j.maturitas. 2012.10.016)

16 Pugeat M, Moulin P, Cousin P, Fimbel S, Nicolas MH, Crave JC \& Lejeune $\mathrm{H}$. Interrelations between sex hormone-binding globulin (SHBG), plasma lipoproteins and cardiovascular risk. Journal of Steroid Biochemistry and Molecular Biology 199553 567-572. (doi:10.1016/ 0960-0760(95)00102-6)

17 Gyllenborg J, Rasmussen SL, Borch-Johnsen K, Heitmann BL, Skakkebaek NE \& Juul A. Cardiovascular risk factors in men: the role of gonadal steroids and sex hormone-binding globulin. Metabolism: Clinical and Experimental 200150 882-888. (doi:10.1053/ meta.2001.24916)

18 Bataille V, Perret B, Evans A, Amouyel P, Arveiler D, Ducimetiere P, Bard JM \& Ferrieres J. Sex hormone-binding globulin is a major determinant of the lipid profile: the PRIME study. Atherosclerosis 2005 179 369-373. (doi:10.1016/j.atherosclerosis.2004.10.029)

19 Haffner SM \& Valdez RA. Endogenous sex hormones: impact on lipids, lipoproteins, and insulin. American Journal of Medicine 199598 40S-47S. (doi:10.1016/S0002-9343(99)80058-8)

20 Haffner SM, Newcomb PA, Marcus PM, Klein BE \& Klein R. Relation of sex hormones and dehydroepiandrosterone sulfate (DHEA-SO4) to cardiovascular risk factors in postmenopausal women. American Journal of Epidemiology 1995142 925-934.

21 Birkeland KI, Hanssen KF, Torjesen PA \& Vaaler S. Level of sex hormone-binding globulin is positively correlated with insulin sensitivity in men with type 2 diabetes. Journal of Clinical Endocrinology and Metabolism 199376 275-278.
22 Nestler JE \& Strauss JF. Insulin as an effector of human ovarian and adrenal steroid metabolism. Endocrinology and Metabolism Clinics of North America 199120 807-823.

23 Reaven GM \& Laws A. Insulin resistance, compensatory hyperinsulinaemia, and coronary heart disease. Diabetologia 199437 948-952. (doi:10.1007/BF00400953)

24 Xun P, Wu Y, He Q \& He K. Fasting insulin concentrations and incidence of hypertension, stroke, and coronary heart disease: a metaanalysis of prospective cohort studies. American Journal of Clinical Nutrition 201398 1543-1554. (doi:10.3945/ajcn.113.065565)

25 Plymate SR, Leonard JM, Paulsen CA, Fariss BL \& Karpas AE. Sex hormone-binding globulin changes with androgen replacement. Journal of Clinical Endocrinology and Metabolism 198357 645-648. (doi:10.1210/jcem-57-3-645)

26 Longcope C, Goldfield SR, Brambilla DJ \& McKinlay J. Androgens, estrogens, and sex hormone-binding globulin in middle-aged men. Journal of Clinical Endocrinology and Metabolism 199071 1442-1446. (doi:10.1210/jcem-71-6-1442)

27 Yeap BB. Androgens and cardiovascular disease. Current Opinion in Endocrinology, Diabetes, and Obesity 201017 269-276. (doi:10.1097/ MED.0b013e3283383031)

28 Chubb SA, Hyde Z, Almeida OP, Flicker L, Norman PE, Jamrozik K, Hankey GJ \& Yeap BB. Lower sex hormone-binding globulin is more strongly associated with metabolic syndrome than lower total testosterone in older men: the Health in Men Study. European Journal of Endocrinology 2008158 785-792. (doi:10.1530/EJE-07-0893)

29 Muller M, van den Beld AW, Bots ML, Grobbee DE, Lamberts SW \& van der Schouw YT. Endogenous sex hormones and progression of carotid atherosclerosis in elderly men. Circulation 2004109 2074-2079. (doi:10.1161/01.CIR.0000125854.51637.06)

30 Rantakallio P. The longitudinal study of the northern Finland birth cohort of 1966. Paediatric and Perinatal Epidemiology 19882 59-88. (doi:10.1111/j.1365-3016.1988.tb00180.x)

31 Vartiainen E, Jousilahti P, Alfthan G, Sundvall J, Pietinen P \& Puska P. Cardiovascular risk factor changes in Finland, 1972-1997. International Journal of Epidemiology 200029 49-56. (doi:10.1093/ije/29.1.49)

32 Vermeulen A, Verdonck L \& Kaufman JM. A critical evaluation of simple methods for the estimation of free testosterone in serum. Journal of Clinical Endocrinology and Metabolism 199984 3666-3672. (doi:10.1210/jcem.84.10.6079)

33 Alberti KG, Eckel RH, Grundy SM, Zimmet PZ, Cleeman JI, Donato KA, Fruchart JC, James WP, Loria CM \& Smith SC. Harmonizing the metabolic syndrome: a joint interim statement of the International Diabetes Federation Task Force on Epidemiology and Prevention; National Heart, Lung, and Blood Institute; American Heart Association; World Heart Federation; International Atherosclerosis Society; and International Association for the Study of Obesity. Circulation 2009120 1640-1645. (doi:10.1161/CIRCULATIONAHA.109.192644)

34 Matthews DR, Hosker JP, Rudenski AS, Naylor BA, Treacher DF \& Turner RC. Homeostasis model assessment: insulin resistance and $\beta$-cell function from fasting plasma glucose and insulin concentrations in man. Diabetologia 198528 412-419. (doi:10.1007/BF00280883)

35 Firtser S, Juonala M, Magnussen CG, Jula A, Loo BM, Marniemi J, Viikari JS, Toppari J, Perheentupa A, Hutri-Kahonen N et al. Relation of total and free testosterone and sex hormone-binding globulin with cardiovascular risk factors in men aged 24-45 years. The Cardiovascular Risk in Young Finns Study. Atherosclerosis 2012222 257-262. (doi:10.1016/j.atherosclerosis.2012.02.020)

36 Daka B, Rosen T, Jansson PA, Larsson CA, Rastam L \& Lindblad U. Low sex hormone-binding globulin is associated with hypertension: a crosssectional study in a Swedish population. BMC Cardiovascular Disorders 201313 30. (doi:10.1186/1471-2261-13-30)

37 Kweon SS, Shin MH, Nam HS, Jeong SK, Park KS, Choi JS \& Lee YH. Sex differences in the associations of testosterone and sex hormonebinding globulin with metabolic syndrome in middle-aged and elderly 
Koreans: the Namwon study. Circulation Journal 201377 734-740. (doi:10.1253/circj.CJ-12-0613)

38 Matsumoto AM \& Bremner WJ. Serum testosterone assays - accuracy matters. Journal of Clinical Endocrinology and Metabolism 200489 520-524. (doi:10.1210/jc.2003-032175)

39 Sartorius G, Ly LP, Sikaris K, McLachlan R \& Handelsman DJ. Predictive accuracy and sources of variability in calculated free testosterone estimates. Annals of Clinical Biochemistry 200946 137-143. (doi:10.1258/acb.2008.008171)

40 Coviello AD, Haring R, Wellons M, Vaidya D, Lehtimaki T, Keildson S, Lunetta $\mathrm{KL}, \mathrm{He} \mathrm{C}$, Fornage $\mathrm{M}$, Lagou $\mathrm{V}$ et al. A genome-wide association meta-analysis of circulating sex hormone-binding globulin reveals multiple Loci implicated in sex steroid hormone regulation. PLoS Genetics 20128 e1002805. (doi:10.1371/journal.pgen.1002805)

$41 \mathrm{Wu}$ FC \& von Eckardstein A. Androgens and coronary artery disease. Endocrine Reviews 200324 183-217. (doi:10.1210/er.2001-0025)

42 Sorva R, Kuusi T, Dunkel L \& Taskinen MR. Effects of endogenous sex steroids on serum lipoproteins and postheparin plasma lipolytic enzymes. Journal of Clinical Endocrinology and Metabolism 198866 408-413. (doi:10.1210/jcem-66-2-408)

43 Desmeules A, Couillard C, Tchernof A, Bergeron J, Rankinen T, Leon AS, Rao DC, Skinner JS, Wilmore JH, Despres JP et al. Post-heparin lipolytic enzyme activities, sex hormones and sex hormone-binding globulin (SHBG) in men and women: the HERITAGE Family Study. Atherosclerosis 2003171 343-350. (doi:10.1016/j.atherosclerosis. 2003.08.018)

44 Malkin CJ, Pugh PJ, Jones RD, Kapoor D, Channer KS \& Jones TH. The effect of testosterone replacement on endogenous inflammatory cytokines and lipid profiles in hypogonadal men. Journal of Clinical Endocrinology and Metabolism 200489 3313-3318. (doi:10.1210/ jc.2003-031069)

45 Kienitz T \& Quinkler M. Testosterone and blood pressure regulation. Kidney \& Blood Pressure Research 200831 71-79. (doi:10.1159/ 000119417)

46 Malkin CJ, Pugh PJ, Jones RD, Jones TH \& Channer KS. Testosterone as a protective factor against atherosclerosis - immunomodulation and influence upon plaque development and stability. Journal of Endocrinology 2003178 373-380. (doi:10.1677/joe.0.1780373)

47 Pugh PJ, Channer KS, Parry H, Downes T \& Jone TH. Bio-available testosterone levels fall acutely following myocardial infarction in men: association with fibrinolytic factors. Endocrine Research 200228 161-173. (doi:10.1081/ERC-120015055)

48 Ruige JB, Mahmoud AM, De Bacquer D \& Kaufman JM. Endogenous testosterone and cardiovascular disease in healthy men: a metaanalysis. Heart 201197 870-875. (doi:10.1136/hrt.2010.210757)

49 Ohlsson C, Barrett-Connor E, Bhasin S, Orwoll E, Labrie F, Karlsson MK, Ljunggren O, Vandenput L, Mellstrom D \& Tivesten A. High serum testosterone is associated with reduced risk of cardiovascular events in elderly men. The MrOS (Osteoporotic Fractures in Men) study in
Sweden. Journal of the American College of Cardiology 201158 1674-1681. (doi:10.1016/j.jacc.2011.07.019)

50 Basaria S, Coviello AD, Travison TG, Storer TW, Farwell WR, Jette AM, Eder R, Tennstedt S, Ulloor J, Zhang A et al. Adverse events associated with testosterone administration. New England Journal of Medicine 2010 363 109-122. (doi:10.1056/NEJMoa1000485)

51 Haring R, Teumer A, Volker U, Dorr M, Nauck M, Biffar R, Volzke H, Baumeister SE \& Wallaschofski H. Mendelian randomization suggests non-causal associations of testosterone with cardiometabolic risk factors and mortality. Andrology 2013 117-23. (doi:10.1111/j. 2047-2927.2012.00002.x)

52 Tajar A, Forti G, O'Neill TW, Lee DM, Silman AJ, Finn JD, Bartfai G, Boonen S, Casanueva FF, Giwercman A et al. Characteristics of secondary, primary, and compensated hypogonadism in aging men: evidence from the European Male Ageing Study. Journal of Clinical Endocrinology and Metabolism 201095 1810-1818. (doi:10.1210/jc.2009-1796)

53 Bellido T, Jilka RL, Boyce BF, Girasole G, Broxmeyer H, Dalrymple SA, Murray R \& Manolagas SC. Regulation of interleukin-6, osteoclastogenesis, and bone mass by androgens. The role of the androgen receptor. Journal of Clinical Investigation 199595 2886-2895. (doi:10.1172/JCI117995)

54 Ohlsson C, Wallaschofski H, Lunetta KL, Stolk L, Perry JR, Koster A, Petersen AK, Eriksson J, Lehtimaki T, Huhtaniemi IT et al. Genetic determinants of serum testosterone concentrations in men. PLoS Genetics 20117 e1002313. (doi:10.1371/journal.pgen.1002313)

55 Feldman HA, Longcope C, Derby CA, Johannes CB, Araujo AB, Coviello AD, Bremner WJ \& McKinlay JB. Age trends in the level of serum testosterone and other hormones in middle-aged men: longitudinal results from the Massachusetts male aging study. Journal of Clinical Endocrinology and Metabolism 200287 589-598. (doi:10.1210/ jcem.87.2.8201)

56 Yeap BB, Almeida OP, Hyde Z, Norman PE, Chubb SA, Jamrozik K \& Flicker L. In men older than 70 years, total testosterone remains stable while free testosterone declines with age. The Health in Men Study. European Journal of Endocrinology 2007156 585-594. (doi:10.1530/ EJE-06-0714)

57 Vermeulen A, Kaufman JM \& Giagulli VA. Influence of some biological indexes on sex hormone-binding globulin and androgen levels in aging or obese males. Journal of Clinical Endocrinology and Metabolism $1996 \mathbf{8 1}$ 1821-1826. (doi:10.1210/jcem.81.5.8626841)

58 Assmann G, Cullen P, Jossa F, Lewis B \& Mancini M. Coronary heart disease: reducing the risk: the scientific background to primary and secondary prevention of coronary heart disease. A worldwide view. International Task force for the Prevention of Coronary Heart disease. Arteriosclerosis, Thrombosis, and Vascular Biology 199919 1819-1824. (doi:10.1161/01.ATV.19.8.1819)

59 Lawlor DA, Harbord RM, Sterne JA, Timpson N \& Davey Smith G. Mendelian randomization: using genes as instruments for making causal inferences in epidemiology. Statistics in Medicine $2008 \mathbf{2 7}$ 1133-1163. (doi:10.1002/sim.3034)

Received 20 December 2013

Revised version received 7 March 2014

Accepted 26 March 2014 